ASEAN Journal of Science and
Engineering Education

\title{
Short Play Approach for Analytical Chemistry Class
}

\author{
Mohd Dzul Hakim Wirzal', Nur Syakinah Abd Halim \\ Chemical Engineering Department, Universiti Teknologi PETRONAS,32610, Bandar Seri Iskandar, Perak, \\ Malaysia \\ Correspondence: E-mail: mdzulhakim.wirzal@utp.edu.my
}

\begin{abstract}
A B S T R A C T S
In this era, cooperative learning strategies have been practiced extensively as an alternative to conventional teaching methods. This is because some of the conventional methods are no longer suitable to be applied to the younger generation. Cooperative learning strategies such as role-play for instance are recommended in nurturing the exciting vibe of learning in class while at the same time boosting the students' confidence level. In this case study, a total of 106 students in the $3^{\text {rd }}$ Year in the $2^{\text {nd }}$ Semester under the Chemical Engineering Department of Universiti Teknologi PETRONAS were involved in a short-play approach for the subject of Analytical Chemistry. It is found that the short-play approach effectively improved the basic understanding of students towards the Analytical Chemistry subject. Furthermore, the majority of the students also scores better in the final exam as compared during the test.
\end{abstract}

\author{
A R T I C L E I N F O \\ Article History: \\ Submitted/Received 18 Nov 2022 \\ First revised 28 Dec 2022 \\ Accepted 04 Jan 2022 \\ First available online 05 Jan 2022 \\ Publication date 01 Sep 2022 \\ Keyword: \\ Analytical chemistry, \\ Live performance, \\ Role-play.
}




\section{INTRODUCTION}

Over the years, numerous research has been conducted to highlight the effectiveness of cooperative learning strategies. We have reached the era where some of the conventional teaching methods are no longer suitable to be applied to the younger generation. A learning environment that is high pressured and teacher-directed will create an intense atmosphere for the students (Kessel, 2018). Besides that, complicated human factors and resources limitation can also create discomfort among students during the learning activities (Mohamad et al., 2021). To adapt to their learning styles, cooperative learning strategies were applied. One of the methods in cooperative learning strategies is role-playing (Jackson \& Walters, 2000).

A short-play or role-play teaching can be defined as the activity of acting out or imitating by a small group of people consisting of fewer than 6 people (Félix-Brasdefer, 2010). These people play their role by mimicking an exaggerated behavior pattern (Jackson \& Walters, 2000). Role-playing enables students to experience a whole new world in the learning process in which they will have the opportunities to explore certain specific roles and allow them to compromise without alienation. Few studies have reported the effectiveness of role-playing as a part of the teaching method. When comparing the opinions of students, graduates, doctoral students, professionals, and the authors of classes, it was found that the authors are most particular about judging the impact of their classes on the further vocational career of graduates. They have decided that the role-playing teaching approach is interesting and exciting for both students and lecturers.

This case study involves the participation of 106 students in the $3^{\text {rd }}$ Year in the $2^{\text {nd }}$ Semester under the Chemical Engineering Department of Universiti Teknologi PETRONAS for the subject of Analytical Chemistry. In this subject, overall, there is the four-course outcome, which is named $\mathrm{CO} 1, \mathrm{CO} 2, \mathrm{CO} 3$, and $\mathrm{CO} 4$. These four-course outcomes will be the guidance of the students' performance throughout their studies in this subject. The course outcomes are as followed:

(i) CO1: Understand the principle of analytical chemistry, analytical methodology and apply the statistic method in data handling for reliability and significant derived results.

(ii) CO2: Apply and select the knowledge of materials in chemical processes. Describe the procedures and applications of analytical techniques within the area of gravimetric.

(iii) CO3: Explain the basic principles and analyze the data generated using the spectrophotometric, spectroscopic, and chromatographic methods.

(iv) CO4: Apply the knowledge of analytical and associated data handling and processing skills in laboratory experiments.

Apart from that, the constructive alignment of this study was based on three major connecting factors, lecturer extension, T\&L activities, and assessment. For lecturer extension, our focus would be on CO1. Following this course outcome, the student will conduct T\&L activities which in this case a short play where the script and the performance will be based on analytical topics. From this, students will gain knowledge of analytical chemistry from Chapter 1 until Chapter 8 and will undergo an assessment to test their knowledge on this subject.

\section{METHODS}

\subsection{Flow}

For the flow of this short play project, it will be based on five main components which are grouping, duration, theme, script, and performance. All 106 students will be divided into 
several groups consisting of 5 to 6 students and the selection will be based on their CGPA. As for the duration, the short play needs to be conducted within 7-10 minutes. Furthermore, the theme of the short play will be solely based on the analytical chemistry topic from Chapter 1 until Chapter 8. As for the scriptwriting, the contents should include information or facts about analytical chemistry related. Lastly, students may include set or props, makeup, costume, music, and any technical stuff to their live performance, besides having at least three of their members perform in the short play. The flow chart of this study is illustrated in Figure 1.

\subsection{Evaluation}

Two evaluation sets were prepared to assess the students' performance. They were evaluated based on their scriptwriting and live performance. The script will be evaluated based on format, character, plot, dialog, content, and overall script. As for the performance, it is based on physical performance, character, voice projection, dialog, technical aspect, and overall performance.

\section{RESULTS AND DISCUSSION}

\subsection{Surveys}

After the students performed their short play, a survey was conducted to study the students' reflections regarding the implementation of the short play for this subject. We found that all the students strongly agreed (more than 90\%) to give 4-5 for their rate on the short play approach in AChem Subject (Figure 1). The rate was set from 1 - 5 (Lowest to Highest). As for their learning process, $80 \%$ of the students agreed that short play helps to improve their understanding of the subject as can be seen in Figure $\mathbf{2}$.

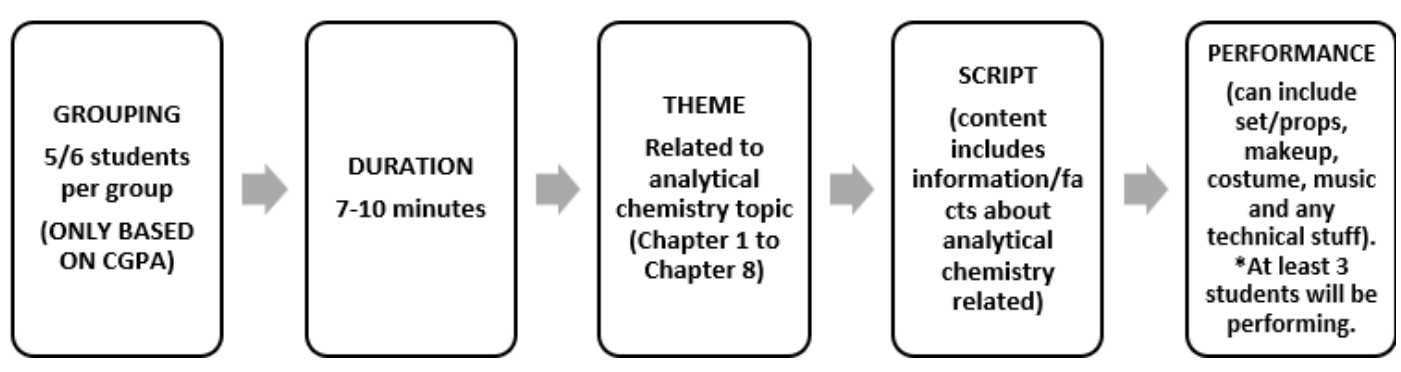

Figure 1. Flow chart of the study.

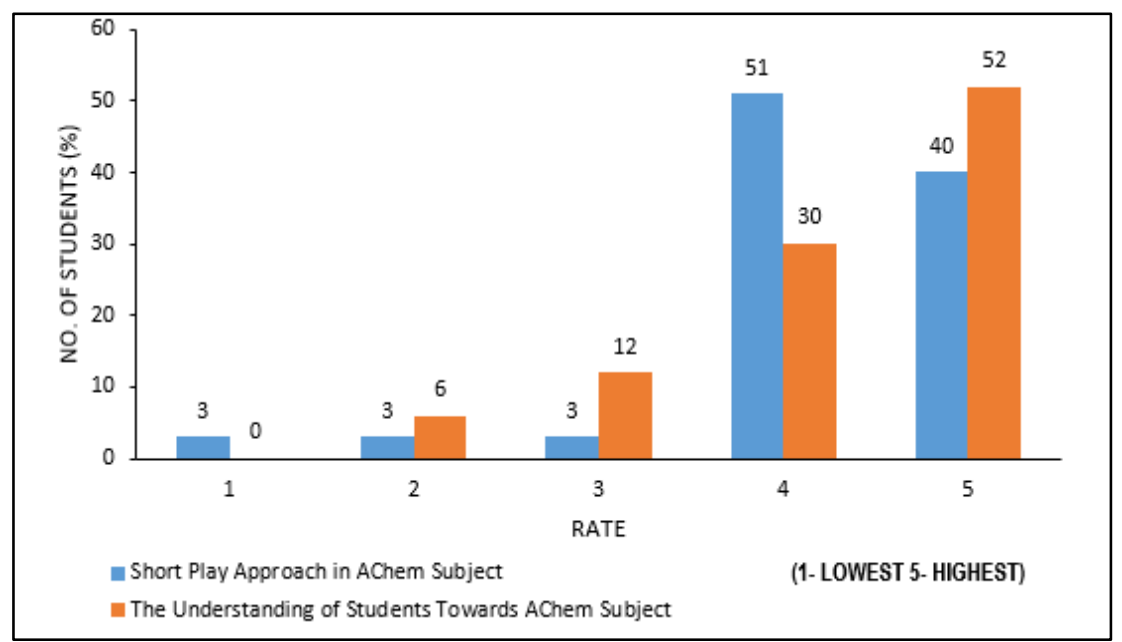

Figure 2. Surveys of students on short play approach. 


\subsection{Students' Results}

Apart from that, it was found that the number of students' scores in the final exam is higher than during the test based on Figure 3. The application of short play can reduce the number of students getting failed. Based on this data, it shows the high impact of short play as a learning tool in Analytical Chemistry and how it successfully able to develop the basic understanding of students towards this particular subject as reported by Jackson and Walter (2000). Metz (2005) and Smythe and Higgins (2007) also stated that role-play activity gives better authentic learning, develops several perspectives, and helps to sharpen their presentation skills. The role-play activities conducted by the lecturer and students were illustrated in Figures $\mathbf{4}$ and $\mathbf{5 .}$

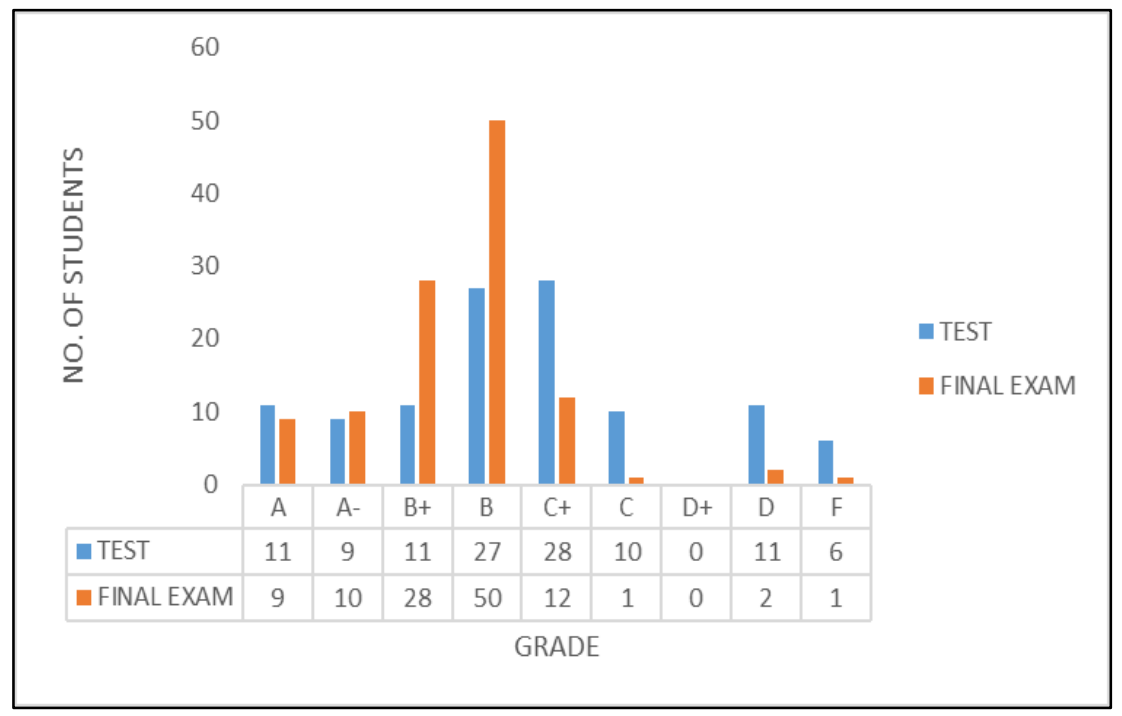

Figure 3. Students' results.

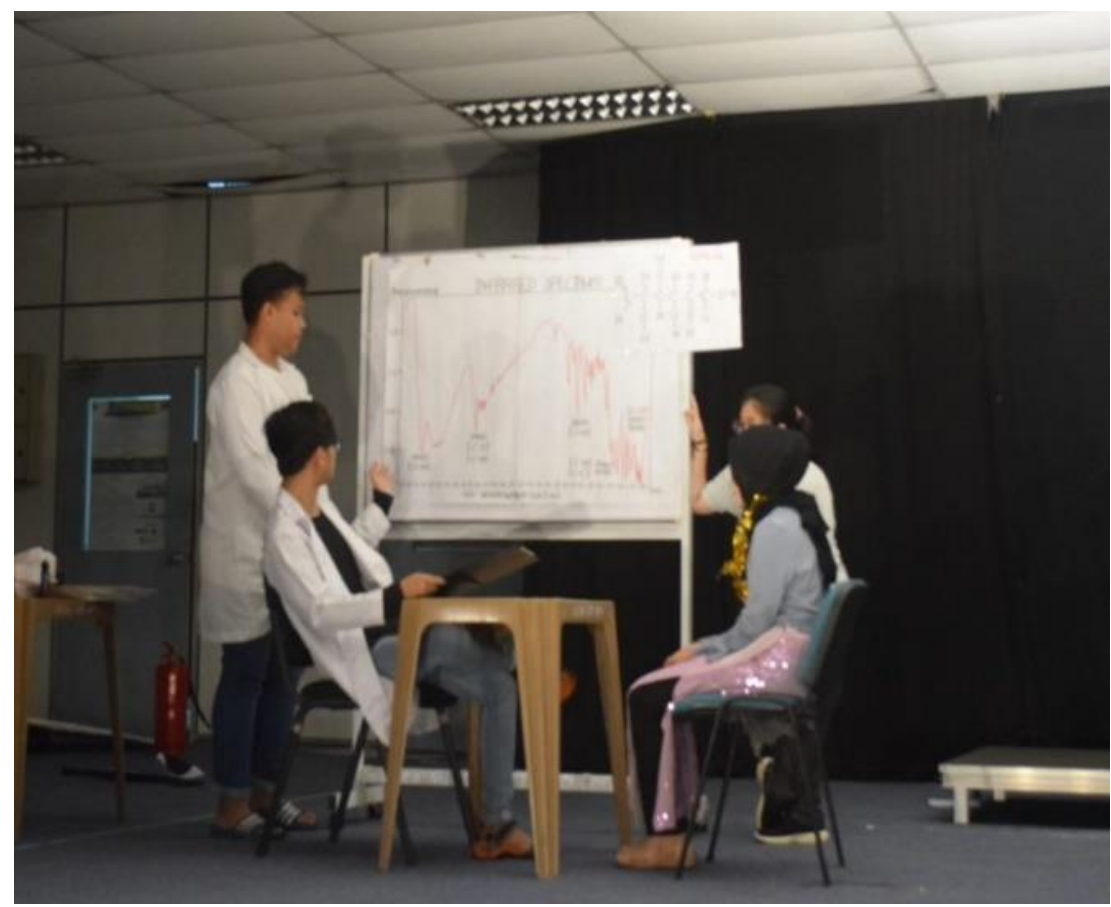

Figure 4. Role-play activities. 


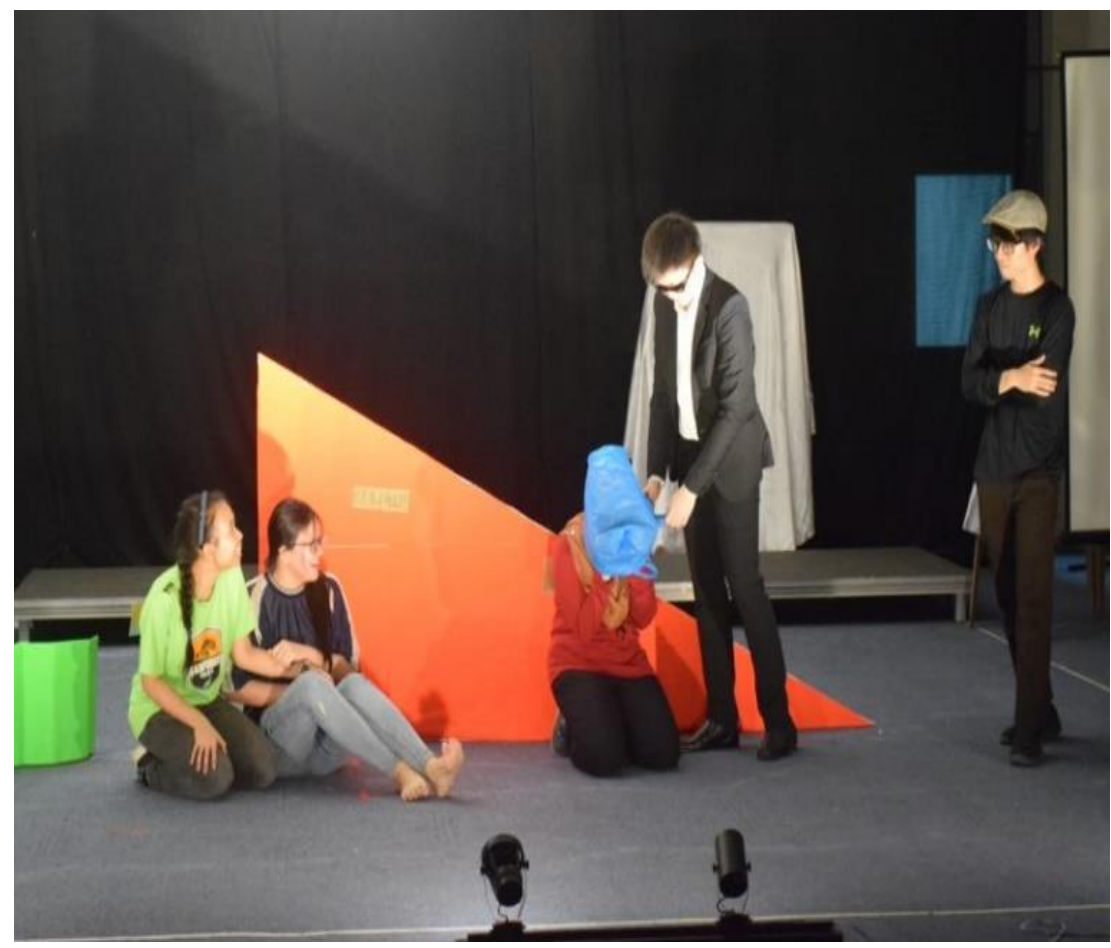

Figure 5. Role-play activities.

\subsection{Issues and Challenges}

To investigate the issues and challenges of the role play application in this subject, the students were asked to write a few reflections on their experience, success, failure, and improvement that they faced during the process. Based on the obtained data, many gave positive feedbacks. For them, role play is an exciting platform for learning and at the same time, boosts their confidence especially in front of the public. It was an engaging experience that gave them a sweet escape from other stressful projects. Nevertheless, few felt that this role play project stressful as it is time-consuming due to a lot of submissions at the moment and it only contributed to the low percentage of the coursework. Apart from that, some of the groupmates did not give cooperation during the process. Therefore, few suggested that the role-play activity can be conducted in the early of the semester and the topics may be given to each group beforehand based on a first come first basis.

\subsection{Value Added}

The short play approach has successfully implanted several added values towards students' development. The fun learning concept can instill students' confidence and creativity, develop philosophical and neutrophilic understanding, and students can explore specific roles and compromise without alienation.

\subsection{Commercialization Potential}

The short play approach has remarkable commercialization potential such as its application for engineering courses and it can be part of marketing strategies for universities. The freedom of expression through learning can be a selling point toward marketing strategies. 


\section{CONCLUSION}

In conclusion, the short play approach has successfully developed the basic understanding of students towards the Analytical Chemistry subject. Most of the students scored higher in the final exam than during the test. Students are also able to boost their confidence, creativity, and philosophical, as well as neutrophilic thinking with this fun learning concept activity. Moreover, other kinds of science and engineering subjects are highly recommended to apply this short play approach for a more captivating learning journey. From this, the students will not feel intimidated while taking the courses as they have a strong passion for the learning activities.

\section{ACKNOWLEDGMENT}

Universiti Teknologi PETRONAS was acknowledged for providing facilities for conducting role-play activities.

\section{AUTHORS' NOTE}

The authors declare that there is no conflict of interest regarding the publication of this article. The authors confirmed that the paper was free of plagiarism.

\section{REFERENCES}

Félix-Brasdefer, J. C. (2010). Intra-lingual pragmatic variation in Mexico City and San Jose, Costa Rica: A focus on regional differences in female requests. Journal of Pragmatics, 42(11), 2992-3011.

Jackson, P.T. and Walters, J.P. (2000). Role-playing in analytical chemistry: The alumni speak. Journal of Chemical Education, 77(8), 1019.

Kessel, J. (2018). Let our children play: The importance of play in early childhood education. University of Montana Journal of Early Childhood Scholarship and Innovative Practice, 2(1), 5.

Metz, D. (2005). Field based learning in science: Animating a museum experience. Teaching Education, 16(2), 165-173.

Mohamad, M. A., Putra, Z. A., Bilad, M. R., Nordin, N. A. H. M., and Wirzal, M. D. H. (2021). An excel based tool development for scheduling optimization. ASEAN Journal of Science and Engineering Education, 1(1), 7-14.

Smythe, A.M. and Higgins, D.A. (2007). (Role) Playing politics in an environmental chemistry lecture course. Journal of Chemical Education, 84(2), 241. 